\title{
BODY COMPOSITION ANALYSIS ACCORDING TO THE EXERCISE MODALITY IN ADULTS WITH OBESTTY: PLLT STUDY
}

\author{
Liliana Aracely Enríquez del Castillo,, A, B, D Natanael Cervantes Hernández, 2, C \\ Ramón Candia Luján, ${ }^{3, D}$ Luis Alberto Flores Olivares ${ }^{4, D}$
}

\author{
Autonomous University of Chihuahua. Faculty of Physical Culture Sciences. Research laboratories, department of biochemistry and exercise \\ physiology. \\ 1 ORCID: 0000-0001-6125-6526. \\ 2 ORCID: 0000-0002-2652-2195. \\ ${ }^{3}$ ORCID: 0000-0002-9393-4034. \\ ${ }^{4}$ ORCID: 0000-0002-8177-8361.

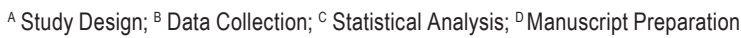

\author{
Address for corpespondence: \\ Liliana Aracely Enriquez del Castillo \\ Circuito Universitario s/n Col. Paseos de Chihuahua. C. P. 31125 \\ E-mail: lenriquez@uach.mx
}

\begin{abstract}
Ahstract Obesity has generated a pandemic in relation to public health; however, depending on the type of exercise, intensity, frequency, and time spent exercising, it provides different effects on the human body. The present investigation has the objective of comparing the effect of two modalities of exercise, aquatic and grounded, on the body composition of overweight and obese adults. The present was an experimental study with 26 overweight and obese adults distributed in two exercise groups: aquatic and grounded. Both groups received 12 weeks of moderate intensity aerobic training assessed with a heart rate monitor and determined through the maximum heart rate on each individual grounded and aquatic training. The study variables were Body Mass Index (BMI), fat percentage, and lean mass. After carrying out the exercise program significant differences were observed in the reduction of BMI as well as in the percentage of fat in both sexes $(<0.01)$. No differences were observed in relation to BMI reduction, nor the percentage of fat evaluated before and after by different exercise modalities; likewise, there was no difference in either sex. In conclusion, exercise provides favorable changes in body composition variables; however, in this study, it does not rely on the exercise modality.
\end{abstract}

Key worlds aerobic exercise, health, physical activity, swimming, training

\section{Introduction}

Obesity is a growing problem in Mexico and all around the world (Vio, 2018), being this of a multifactorial nature (Sánchez-Oliva et al., 2019). Authors suggest that obesity is the product of alterations in the processing and storage of fatty acids and triglycerides (Silva, Inada, Marcelino, Lopes, Aiko, 2017). However, the main attribution is due to an energy imbalance between food and physical activity (Belasco, Pérez, 2018). The type of diet and 
a sedentary lifestyle are related to obesity, but not necessarily to the fat distribution pattern or to the general body composition of the person.

Despite the abundance of information on this subject, it has not yet been possible to efficiently influence the statistics of obesity, so this type of study generates practical values when implementing physical exercise training programs. Between 1975 and 2016, the global prevalence of obesity has almost tripled: in 2016, more than 1.9 billion adults over the age of 18 were overweight, of whom more than 650 million were classified as obese (WHO, 2019). In 2018 The National Health and Nutrition Survey (ENSANUT) reported a $75.2 \%$ prevalence of overweight and obese adults in the domestic population over age 20 (Shamah-Levy et al., 2017).

Obesity is defined as an abnormal or excessive accumulation of fat that can be detrimental to one's health (Estrada, González, Torres, 2018; Cedeño et al., 2015; Engin, 2017), being the source of serious metabolic problems, cardiovascular diseases, and even cancer (WHO, 2019).

A simple way to establish a parameter to determine overweight and obesity is the body mass index (BMI). A BMl above 25 indicates a person is overweight and 30 denotes obesity; however, the percentage of body fat must also be evaluated, with above 25\% inadequate in men and above 32\% in women (Suverza, y Haua, 2010; Cardozo, Cuervo, Murcia, 2016).

With the intention of reducing this problem, it has been established that a regular practice of physical exercise improves important aspects in matters of a person's health; however, depending on the type of exercise, its intensity, frequency, and duration, it has different effects on the human body (Fernández, Quiñones, Robles, Padilla, 2018).

Regarding the environment where the physical activity program takes place, there are some variables that must be considered depending on the population and the objectives of each individual. (Aguilar, 2009; Bernal-Reyes, Peralta-Mendívil, Gavotto-Nogales, Placencia-Camacho, 2014). Aquatic exercise is recommended for people with obesity due to the reduced impact on the individual's joints; while maintaining a level of physical demand that provides benefits to and adaptations to the metabolic level.

Studies show that when physical activity is performed in an aquatic environment, the effects are similar to those achieved on the ground; aspects such as caloric expenditure reaching 1-2 Kcal / min ratings prove this correlation (Rodríguez, Avella, 2015). The global and multi-joint movements used in aquatic environments require a greater number of muscle groups, so aerobic capacity is favored by a higher oxygen expenditure which, consequently, will not only influence muscle cells and capacity of aerobic and anaerobic resistance, but the heart, lungs and vascular system (Rodríguez, Avella, 2015).

Since several studies address the effectiveness of physical exercise in reducing total body weight, there are few investigations that have evaluated different exercise modalities, as they regularly focus on the intensity and type of exercise (aerobic and anaerobic).

In the end, this work's objective does not lie in deepening the role of physical exercise in this multifactorial problem, but in emphasizing the focus on where it is taking place; therefore, due to the above, this research aims to compare the effect of two modalities of supervised physical exercise: aquatic and grounded, as well as the BMI and fat percentage behavior in overweight and obese adults, these being classified by sex, since the intervention of physical exercise programs must focus on a program that safely impacts organs, structures, and systems. 


\section{Material and Methods \\ Participants}

Project registered and approved under folio 13022018-118 by UIP-SIP "Universidad Autónoma de Chihuahua". 41 subjects (21 women and 20 men) with an average age of 29.3 between the age of 18 to 54 years old, were invited through a call issued by the Faculty of Physical Culture Sciences from the Autonomous University of Chihuahua, and prior to enrolling in this physical exercise program had to meet the inclusion criteria, which consisted of undergoing initial and final body composition assessments to determine overweight and/or obesity, living in the state of Chihuahua, Mexico, as well as not having any pathological diseases; while the exclusion criteria included 12 that could not perform physical activity due to an osteoarticular injury or by medical order, elders, pregnant women and being morbidly obese

\section{Measurpes}

To determine each subjects' height, they were asked to stand with their back to a SECA height rod with a sensitivity of $0.1 \mathrm{~cm}$, the result was recorded, at that time, in centimeters plus one decimal.

Body mass measurement was performed in duplicate to obtain the average through the Inner Scan Body Composition monitor BC-568 digital equipment, which has a sensitivity of $0.1 \mathrm{~g}$.

BMI was calculated by dividing the subject's weight in kilograms $(\mathrm{kg})$ by his height in square meters $\left(\mathrm{m}^{2}\right)$. Subjects with a $B M I \geq 25 \mathrm{~kg} / \mathrm{m}^{2}$ were classified as overweight, while those with a BMI $\geq 30 \mathrm{~kg} / \mathrm{m}^{2}$ were classified as obese (WHO, 2018).

Fat percentage and total body weight were determined by the Inner Scan Body Composition monitor BC-568 for which the subjects were asked to remove their socks and stand on the foot position indicator, when it was specified by the monitor, they took the manual devices with their hands and held them for 10 seconds, during which time the team performed the electrical bioimpedance; subsequently, the result appeared on a screen expressed as a percentage.

Monitoring was performed with heart rate monitors duly validated with a SR300X polar equipment, through the perceived effort rate and using the modified Borg Scale (0-10). Each session included a 10-minute neuromuscular conditioning, mobilizing the main muscle groups, raising body temperature as well as lubricating the joints, in water or on ground depending on the case of the exercise modality, as well as a 10-minute cool down period with passive stretching exercises to ensure a progressive return of heart rate.

The pulsations were assessed individually according to the stipulated Karvonen formula: "(Heart rate maximum - heart rate reserve $) \times(\%$ intensity $)+($ resting heart rate); however, it was stipulated that a moderate intensity (40-59\%) should be maintained during the core phase.

\section{Design and procedures}

Quasi-experimental with non-probability sampling study performed from August to November 2019 with pre and post measurements, this study was managed as a pilot study with the intention that it constitutes a prelude to new research on exercise modalities, their differences, and possible benefits. Once these criteria were applied, a total sample of 26 subjects signed an informed consent for voluntary participation in accordance with the Declaration of Helsinki's guidelines (World Medical Association, 2017) and in accordance with the regulations of the General 
Law of Health in Matters of Health Research of the United States of Mexico (Secretaría de Salud, 2014), registered and approved under folio 13022018-118, as well as the PAR-Q questionnaire

The evaluations used in the protocol were taken before and after the 12-week intervention period for all participants, with the final evaluation scheduled for the week following the intervention. Dieting data is not included due to the fact that the objective of the study is to observe the effect of different forms of physical exercise on body composition in obese adults without any other variable affecting the data. The variables evaluated were percentage of fat, $\mathrm{BMI}$, and total body weight.

The design of this exercise program was executed by specific personnel from the Physical Culture Sciences (human motor skills) area and supervised by personnel from the University's research area, with a duration of 12 weeks. Participants performed their physical activity practice in the aquatic or grounded environment, according to their preference, consequently there were 6 men in the water and 9 on a grounded environment, as well as 5 women in the water and 6 on ground, where they had to go 3 non-consecutive days a week. All sessions of both exercises began with the pulsations per minute monitoring at rest, including a minimum of 10 minutes at rest.

The core part in both modalities consisted mainly of aerobic type exercises in the adaptation phase, developing the volume (from 30 to 40 minutes) during the first two weeks. The beats per minute were recorded and perception of effort was assessed with the Borg scale Strategies implemented to maximize adherence including playful aspects within the session, materials for water activities such as elastic worms, boards, gaiters, and pull buoys; while on ground environments consisted mainly of treadmills, outdoor walks, bicycles, rubber bands and free weights.

Each training sessions of 50 to 60 minutes consisted of four main parts: 1) 5-10 minutes of general warmup, including slow walking and stretching in the modality of their preference; 2) the main part was composed of an approximately 30-40-minute-long session with exercises like walking on or around the water, and treadmills or bicycles for grounded environments. Exercises like front and back crawl kick, leg kick on bike, side push with arms and side abdominal in horizontal position, all these exercises were implemented differently in water (30-40 min). The training intensity was maintained at 12-14 in the Borg's RPE. 3) 1-3 sets of resistance exercises with rubber bands and free weights (the resting periods between sets were 40-60 seconds). The exercises involved the major muscle groups including, but not limited to knee flexors/extensors, shoulder abductors/adductors, elbow flexor/ extensor, pectoral, abdominal, etc. To allow a proper adaptation with the exercises and the correct execution and breathing techniques, the training intensity was lower at the beginning of the month. In the preliminary stage, participants performed 8 repetitions for a single set and gradually progressed to 3 sets of 12-15 repetitions. 4) at the end of each session, there was a cool down period of about 5 min involving breathing exercises and stretches on the modality of their preference.

\section{Statistical Analysis}

The statistical analysis was determined in Windows' software SPSS V.15, in which an exploratory analysis was performed, and the data quality was verified by the Kolmogorov-Smirnov method. Distributions and frequencies were explored. Differences between groups $(P<0.05)$ were established by Student's t-test for the analyzed variables compared by sex. 


\section{Results}

The anthropometric variables of the sample divided by sex at the beginning and at the end of the intervention.

We can see that in men and women, the variables of weight, BMI, and body fat decreased significantly and an increase in lean mass was observed, after the application of this physical activity program.

Tahle 1. Anthropometric variables of the sample by sex at the beginning and at the end of the intervention

\begin{tabular}{lccccc} 
& \multicolumn{3}{c}{ Pre } & \multicolumn{1}{c}{ Post } \\
\cline { 2 - 6 } & Mean & SD & Mean & SD & $p$ \\
\hline Weight (kg) & \multicolumn{5}{c}{ Females } \\
BMI (kg/m2) & 81.30 & 12.25 & 77.01 & 12.76 & $<0.001$ \\
Fat mass (\%) & 29.84 & 3.71 & 28.31 & 4.07 & $<0.001$ \\
Lean mass (\%) & 33.14 & 6.44 & 30.14 & 7.46 & $<0.001$ \\
\hline & 66.85 & 6.44 & 69.85 & 7.44 & $<0.001$ \\
\hline Weigth (kg) & & Male & & & \\
BMI (kg/m2) & 90.23 & 16.09 & 83.13 & 15.76 & 0.011 \\
Fat mass (\%) & 29.71 & 3.56 & 27.36 & 3.57 & 0.012 \\
Lean mass (\%) & 28.77 & 2.04 & 25.40 & 1.91 & $<0.001$ \\
\hline
\end{tabular}

SD - Standard desviatión.

The comparisons of the physical activity programs in females, in which it is shown that there is no difference between variables for the type of physical activity they underwent (Figure 1).

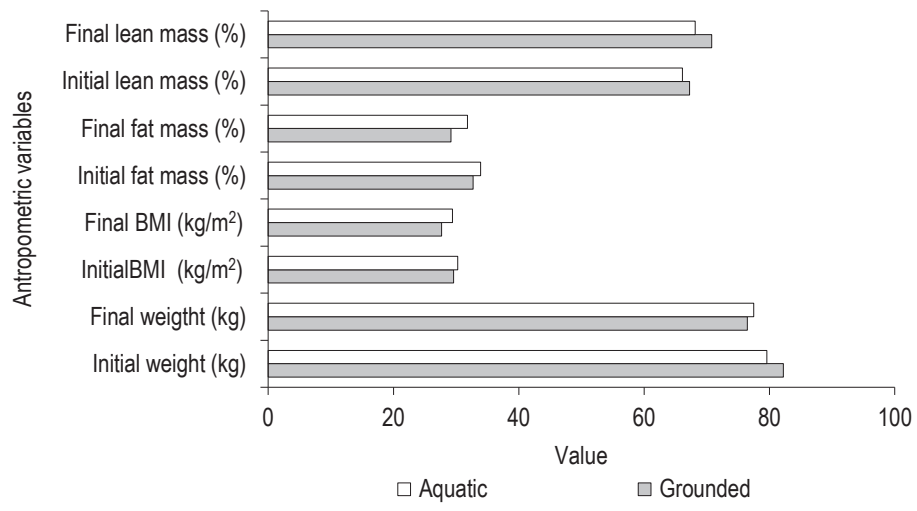

Figure 1. Comparison of exercise programs on anthropometric variables in women

Figure 2 shows the comparisons of the physical activity programs in males, in which it is shown that there is no difference between variables for the type of physical activity they underwent. 


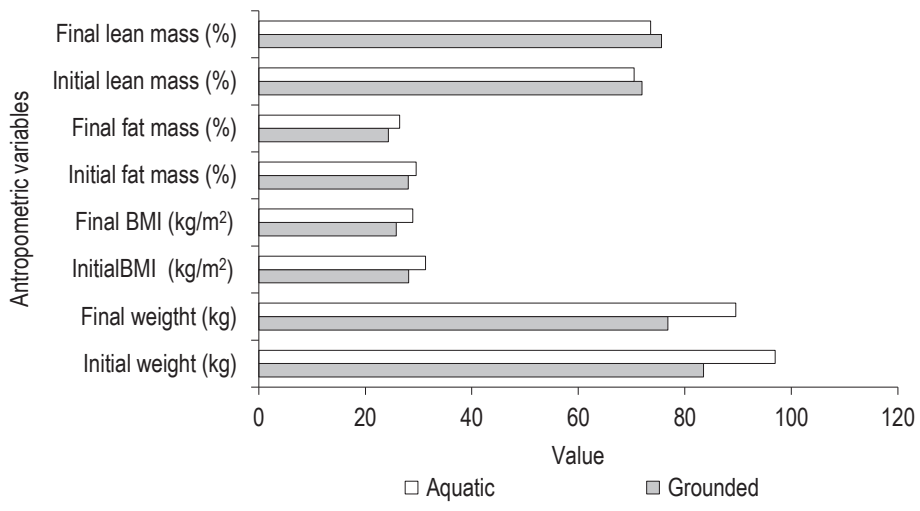

Figure 2. Comparison of exercise programs in anthropometric variables in men

\section{Discussion}

As it is already known, physical activity programs (in different modalities and intensities) are widely recognized as treatment for obesity regardless of sex (Cuadri, Tornero, Sierra, Sáenz, 2018).

No differences were found by sex in the general variables, except for the height since for this program the participants had to be classified as overweight or obese according to the BMI classification; however, fat mass did not generate differences by sex, possibly due to the correlation established with people associated with sedentary behaviors (Leiva et al., 2017).

After the application of this program, the variables of weight, BMI, and fat decreased in men and women. These elements are a simple way of approaching the distribution of different body components, while lean mass increased in both sexes without generating a significant difference between them, thus coinciding with PérezLópez, et al. (2016) in that after 10 weeks of applying a moderate intensity physical exercise program there was a difference in the fat mass of those evaluated. It should be noted that in relation to kilograms, we obtained greater losses in our study ( $4 \mathrm{~kg}$ vs. $1 \mathrm{~kg}$ ), possibly due to the frequency, which was higher ( $3 \mathrm{vs.} 2$ times per week), and the duration of the program.

Although obesity has been related to a deterioration of the muscle that prevents protein catabolism (Bollinger, Powell, Houmard, Witczak, Brault, 2015), after the application of this program, muscle mass was improved, which is expected to have decreased the previously mentioned set of circumstances, such effect was observed in the study by Roberts, Croymans, Aziz, Butch, Lee (2013) in which they obtained significant decrease in fat mass and increase in muscle mass after 12 weeks of exercise with moderate loads of gym training.

Workouts in the aquatic environment have been positioned as favorites due to cardiovascular and metabolic benefits, as well as body composition, with results shown during the study by Pino-Reynals, Espinoza-Navarro, De Arruda, Urizar-Araya (2015), where after 18 weeks of aquatic-aerobic exercise $70 \%$ of the FCM was assessed and they finally managed to increase muscle mass and decrease the sum of folds.

In the Reyes Mancipe study (2018) a $13 \mathrm{~kg}$ decrease in body weight was observed, a higher proportion than in our study; however, the difference lies in the total of sessions, since the Reyes Mancipe study had a total duration 
of 6 months for a physical exercise program on ground, in which the exercises were performed at a high intensity, while in the present study it was 36 weeks at a moderate intensity.

A study by Calero, Maldonado, Fernández, Rodríguez, Enríquez, Rafael (2016) assessed the BMI of obese women modulating the intensity with oscillations of 60 to $85 \%$ in the intervention phase, finding positive results after decreasing a degree of obesity. Another research by Monteiro, Bartolomeu, Forte, Carvalho (2019) found improvements in the BMI of adult women regardless of the type of exercise performed, the types were strength and power training, resistance training and combined. All of them maintain the interval of moderate intensity and in the case of the force repetitions of the 60-80\% 1RM Although the intensities and the components vary, the effects were similar in comparison to the present study.

Similar studies such as that of Sánchez Ortega, Sánchez and García (2014) found a decrease in BMI after 16 sessions of exercise of moderate intensity on ground, achieving a decrease in fat mass $(5.17 \pm 4.03 \mathrm{~kg})$ and a $1.77 \%$ increase of muscle mass, while at the same time Salas-Romero, Sánchez-Muñoz, Franco-Sánchez, del Villar-Morales, Pegueros-Pérez (2014) found similar results with continuous aerobic training sessions on moderate intensity cycling.

It is known that performing 30 minutes a day of moderate physical exercise allows a person to stay healthy, thereby counteracting a sedentary lifestyle; likewise, it has been manifested more recently that where the difference lies is in intensity rather than time.

In a recent study, it was observed that women who perform vigorous physical activity have higher values in power and strength in their legs and a smaller waist circumference due to the physical activity carried out (Enriquez, Cervantes, Candia, Flores, 2021). However, it has shown that greater intensities increase the cardio-metabolic risk. The present research contributes evidence that supports the benefits of moderate physical activity, with a lower risk.

Prieto, Del Valle, Nistal, Mendez, Abelairas-Gomez, Barcala-Furelos (2015) also assessed the body composition of adult women in three different exercise modalities under moderate intensity, in which their emphasis was not based on the training medium, because all 3 were on ground and each of them achieved a decrease in values associated with fat. There was a significant difference between those that were guided by qualified personnel from those who were not. Our study consisted of individualized programs that supervised each participant's performance.

\section{Conclusions}

Supervised physical exercise generates improvements in people's body composition regardless of the type of environment in which it is performed, although the fact that training in the aquatic environment has a wide potential for preventing health risks, it does not generate significant differences related to the decrease in parameters associated with obesity.

To conclude, this pilot study allows us to affirm that despite not modifying eating habits, it is possible to positively modify body composition in overweight-obese patients regardless of the environment in which the exercise is performed as long as an adequate volume of weekly exercise is carried out with supervision by a professional. As a training method, we could suggest moderate intensity in the aquatic environment to minimize the risk of joint overload injuries and maximize aerobic resistance, which is a physical capacity that has a close relationship with health. The constant monitoring of the patient should be considered during the intervention program for the treatment of overweight and obesity. 
It is suggested to continue with this type of study regarding the benefits offered by different exercise modalities in overweight-obese patients, including a greater number of patients and increasing physiological variables that provide us with a greater picture of the effect that exercise can have.

It is necessary to include a healthy diet and nutrition in these programs allowing for a change in life habits that will have a greater effect on the treatment of overweight and obesity.

\section{References}

Aguilar, E. (2009). Bases fisiológicas de los principios del entrenamiento deportivo. Revista politécnica, 5 (8), 84-93. DOI:10.33571/ rpolitec.

Asociación Médica Mundial Declaración de Helsinki (2014). Principios éticos para la investigación en seres humanos. Boletín del Consejo Académico de Ética en Medicina, 1 (2), 239-243. Retrieved from: https://www.wma.net/es/policies-post/ declaracion-de-helsinki-de-la-amm-principios-eticos-para-las-investigaciones-medicas-en-seres-humanos.

Belasco, E., Pérez, M. (2018). Obesidad, un problema de salud pública. El caso español. Archives-ouvertes, 1, 1-14. DOI: 01744058.

Bernal-Reyes, F., Peralta-Mendívil, A., Gavotto-Nogales, H., Placencia-Camacho, L. (2014). Principios de entrenamiento deportivo para la mejora de las capacidades físicas. Biotecnia, 16 (3), 42-49. DOI: 10.18633/bt.v16i3.140.

Bollinger, L., Powell, J., Houmard, J., Witczak, C., Brault, J. (2015). Skeletal muscle myotubes in severe obesity exhibit altered ubiquitinproteasome and autophagic/lysosomal proteolytic flux. Obesity (Silver Spring), 23 (6). 1185-1193. DOI: 10.1002/oby.21081.

Calero, S., Maldonado, I., Fernández, A., Rodríguez. A., Enríquez, O., Rafael N. (2016). Actividades físico-recreativas para disminuir la obesidad en mujeres entre los 35-50 años de edad. Revista Cubana de Investigación Biomédica, 35 (4), 375-386.

Cuadri, J.,Tornero, I., Sierra, A., Sáenz, J. (2018). Revisión sistemática sobre los estudios de intervención de actividad física para el tratamiento de la obesidad. Retos, 33, 261-266.

Engin, A. (2017). The Definition and Prevalence of Obesity and Metabolic Syndrome. Obesity and Lipotoxicity. Advances in Experimental Medicine and Biology, 960, 1-17. DOI: 10.1007/978-3-319-48382-5_1.

Enríquez-Del-Castillo, L., Cervantes-Hernández, N., Candia-Luján, R., Flores L. (2021). Capacidades físicas y su relación con la actividad física y composición corporal en adultos. Retos, 41 (3), 674-683. DOI: 10.47197/retos.v41i0.83067.

Estrada, A., González, C., Torres, M. (2018). Asociación de calidad de dieta y obesidad. Población y Salud en Mesoamérica, 16 (1), 1-19. DOI: 10.15517/psm.v111.32285.

Fernández, J., Quiñones, I., Robles, A., Padilla, J. (2018). Revisión sistemática sobre los estudios de intervención de actividad física para el tratamiento de la obesidad. Retos, 33, 261-266. DOI: 10.47197/retos.v0i33.52996.

Leiva, A.M., Martínez, M.A., Cristi-Montero, C., Salas, C., Ramírez-Campillo, R., Díaz, X., Celis-Morales, C. (2017). El sedentarismo se asocia a un incremento de factores de riesgo cardiovascular y metabólicos independiente de los niveles de actividad física. Revista médica de Chile, 145 (4), 458-467.

Malo-Serrano, M., Castillo, N., Pajita, D. (2017). La obesidad en el mundo. Anales de la Facultad de Medicina, 78 (2), 173-178. DOI: 10.15381/anales.v78i2.13213.

Monteiro, A., Bartolomeu, R., Forte, P., Carvalho, J. (2019). Los efectos de tres tipos diferentes de entrenamiento en la aptitud funcional y la composición corporal en mujeres mayores. Journal of Sport and Health Research, 11 (3), 289-304.

Pérez-López, A., Santiago, J., Merino, P., Sánchez, C., Valverde, I., Valverde, B., Cerrato D. (2016). Beneficios de un programa de ejercicio físico con autocargas y materiales reciclados sobre la composición corporal y la condición física en tercera edad: estudio piloto. Revista Española de Educación Física y Deportes, 413, 21-32.

Pino-Reynals, A., Espinoza-Navarro, O., De Arruda, M, Urizar-Araya, C. (2015). Composición Corporal y Somatotipo de Mujeres de Entre 16 a 18 Años: Efecto de un Programa Acuático-Aeróbico en el Mejoramiento de la Fuerza Muscular. International Journal of Morphology, 33 ( 4), 1213-1219. DOI: 10.4067/S0717-95022015000400003.

Prieto, J., Del-Valle, M, Nistal, P., Mendez, D, Abelairas-Gomez, C., Barcala-Furelos, R. (2015). Impact of exercise on the body composition and aerobic capacity of elderly with obesity through three models of intervention. Nutrición hospitalaria, 31 (3), 1217-1224. DOI: 10.3305/nh.2015.31.3.8434.

Roberts, C., Croymans, D., Aziz, N., Butch, A., Lee, C. (2013). Resistance training increases SHBG in overweight/obese, young men. Metabolism clinical and experimental, 62 (1), 725-733, DOI: 10.1016/j.metabol.2012.12.004. 
Rodríguez. M., Avella, R. (2015). Beneficios del desarrollo de la fuerza y la resistencia en el medio acuático. Revista digital: Actividad Física y Deporte, 1 (1), 83-94.

Salas-Romero, R., Sánchez-Muñoz, V., Franco-Sánchez, J., Del Villar-Morales, A., Pegueros-Pérez, A. (2014). Efectividad de dos modalidades de ejercicio aeróbico en el tratamiento de pacientes con síndrome metabólico (SM). Estudio preliminar. Gaceta Médica de México, 150 (6), 490-498.

Sánchez, L., Sánchez, C., Garcia, A. (2014). Valoración de un programa de ejercicio físico estructurado en pacientes con obesidad mórbida pendientes de cirugía bariátrica. Nutrición hospitalaria, 29 (1), 64-72. DOI: 10.3305/nh.2014.29.1.6937.

Sánchez-Oliva, D., Esteban-Cornejo, I., Padilla-Moledo, C., Pérez-Bey, A., Veiga, O., Cabanas-Sánchez, V., Castro-Piñero, J. (2019). Associations between physical activity and sedentary time profiles transitions and changes in well-being in youth: The up \& down Iongitudinal study. Psychology of Sport and Exercise, 101588. 1-8, DOI: 10.1016/j.psychsport.2019.101558.

Secretaria de Salud. (2014). Reglamento de la ley general de salud en materia de investigación para la salud. Retrieved from: https:/l www.ssaver.gob.mx/transparencia/files/2011/11/Reglamento-de-la-Ley-General-en-materia-de-Investigaci\%C3\%B3n.pdf.

Shamah-Levy, T., Ruiz-Matus, C., Rivera-Dommarco, J., Kuri-Morales, P., Cuevas-Nasu, L., Jiménez-Corona, M. (2017). Encuesta Nacional de Salud y Nutrición de Medio Camino 2016. Resultados Nacionales. Cuernavaca, México: Instituto Nacional de Salud Pública. Retrieved from: http://spmediciones.mx/libro/encuesta-nacional-de-salud-y-nutricion-de-medio-camino-2016_50142.

Silva, P., Inada, C., Marcelino, G., Lopes, C., Aiko, H. (2017). Fatty acids consumption: the role metabolic aspects involved in obesity and its associated disorders. Nutrients, 9 (10), 1158. DOI: 10.3390/nu9101158.

Vio, F. (2018). Aumento de la obesidad en chile yen el mundo. Revistachilena de nutrición, 45,6.DOI: 10.4067/s0717-75182018000100006.

World Health Organization (2019). Estrategia mundial sobre régimen alimentario, actividad física y salud. Ginebra, Suiza. Retrieved from: https://www.who.int/dietphysicalactivity/es.

Suverza, A. y Haua, K. (2010) El ABCD de la evaluación del estado de nutrición. México: McGraw-Hill.

Cardozo, L.A., Cuervo, Y., Murcia, J. (2016). Porcentaje de grasa corporal y prevalencia de sobrepeso-obesidad en estudiantes universitarios de rendimiento deportivo de Bogotá, Colombia. Nutrición clínica y dietética hospitalaria, 36 (3), 68-75.

Reyes Mancipe, C.J. (2018). Evaluación de las variaciones antropométricas en una persona sedentaria, a partir de la aplicación de un programa de entrenamiento funcional, implementando técnicas específicas de CrossFit, TRX y CORE (Doctoral dissertation, Universidad Nacional de La Plata. Facultad de Humanidades y Ciencias de la Educación).

Cite this article as:: Enriquez-Del Castillo, L.A., Cervantes Hernández, N., Candia Luján, R., Flores Olivares, L.A. (2021). Body Composition Analysis According to the Exercise Modality in Adults with Obesity: Pilot Study. Central European Journal of Sport Sciences and Medicine, 2 (34), 87-95. DOI: 10.18276/cej.2021.2-08. 